\title{
Attitude of the Students towards the Usage of Group Activities as a Remedy for Secondary Language Speaking Anxiety
}

\author{
Peiris, A.E. \\ ashani.p@sliit.lk \\ English Language Teaching Unit (ELTU), School of Natural Science, Faculty of Humanities and \\ Sciences, SLIIT, Malabe, Sri Lanka
}

\begin{abstract}
As literature suggests Second Language (L2) speaking has always been a challenge for students. One of the main issues is the apprehension occurring when a learner is expected to perform in the second language. As facilitators at the tertiary level, it is vital to create a low-anxiety classroom to help students with L2 speaking anxiety. This research attempts to investigate the perspective of students towards using group activities to reduce speaking anxiety in the English as a Second Language (ESL) classroom. The sample group consisted of forty-five Post Advanced Level Students from an intensive course in a private institute. A questionnaire prior to any speaking activity and weekly questionnaires while conducting both group and individual speaking activities were given to this mixed ability group for three weeks to study their attitude towards L2 speaking. Initial findings were that majority (86.7\%) of students were afraid of L2 speaking due to several reasons. However, that percentage was dropped to $56.5 \%$ and $38.7 \%$ at the second and third week respectively irrespective of the medium of communication at school, and the usage of English at home. . In contrast the initial percentage of not afraid of L2 speaking (13.3\%) was increased to $43.5 \%$ and $61.3 \%$ respectively at second and third week. These results clearly indicate that the students preferred group activities more than individual activities. Group activities have helped the students to make an effort to speak as there were students who did speaking activities for the first time in their life. It is recommended that group activities can be used to a certain extent as an effective tool to reduce speaking anxiety.
\end{abstract}

Key words: Attitude, Effectiveness, Group Activities, Language Anxiety, Speaking Skills.

\section{Introduction}

One of the biggest challenges faced by the second and foreign language learners is Speech Anxiety (Young,1992). Over the years many researchers like Horwits et al, (1986) and Pribyl et al. (2001) have been discussing about foreign language anxiety, and new approaches have been explored to aid the foreign language learners with this challenge.
One reason can be lack of prominence given to language-specific needs of learners when developing the curriculum (Attanayake, 2020). When facilitating English at both secondary and tertiary levels, it is important for the facilitators to be aware of such approaches to minimize anxiety and help the students. 


\section{Language Anxiety}

Language anxiety is the fear or apprehension occurring when a learner is expected to perform in the second language or the negative emotional reaction when learning or using a second language (Gardner and MacIntyre, 1993). McCroskey and Beatty (1986) add to this interpretation, and they highlight the effects of Communication Apprehension. Woodrow (2006) further highlights the debilitating effect anxiety causes in a learners' speaking capability. Such speakers tend to avoid communication and as a result, they will lose the opportunity to experience the practice that is required to develop true competence in the language. McCroskey and Beatty (1986) and Daubney (2005) add to this by saying that the negative anxiety weakens the students' resolve, creates doubts, encourages them to run away and debilitates. According to Woodrow (2006), oral presentations and performing in front of a class are the most reported stressors in class situations. Thus, it is vital to explore methods to reduce L2 speech anxiety irrespective of the context to help the students.

\section{Remedies to aid speech anxiety}

Teaching methodologies like Community Language learning can be used to help anxiety and to create a supportive environment. On the other hand, researchers have been investigating new remedies to help Speech anxiety. Some major treatment approaches include cognitive-oriented treatments, and systematic desensitization (Wolpe, 1958). Other than these treatments, different methods have been suggested throughout the years to create a low-anxiety classroom. Language games are one such method. Games can be used to create interest, motivate students, encourage participation, and reduce language anxiety (Saunders \& Daniel, 1985). As Young (1992) had discussed having students discuss in small groups or pairs, using relaxation techniques, deep breathing, meditation and music can be used to reduce anxiety in the classroom.

Among these methods, the effective usage of group activities has been discussed (Young, 1992; Neer \& Kirchner,1991). As observed over the years, there is a reluctance among students to participate in group activities actively and equally, especially the students with speech anxiety do not actively participate in such activities. As facilitators, it is vital to know the attitude of the students towards the usage of group activities as a remedy for L2 speaking anxiety in order to help them better.

In view of the above explanation, the objective of this research is to investigate the attitude of the students towards the usage of Group Activities as a remedy for Speaking Anxiety.

\section{Materials and Methods Sample}

To collect data, a sample group of forty-five Post Advanced Level Students who have got registered for an Intensive course to read for a degree were randomly selected. They were from a mixed ability ESL class. This sample group was selected because they were just after their secondary education and were not exposed to tertiary education. 


\section{Data collection}

Questionnaires and observations were used as the data gathering tool. Initially a questionnaire to study their attitude towards L2 speaking was given. Then within a time span of three weeks both group and individual speaking activities were conducted during their Communication Skills module. Within three weeks, group activities like roleplays, mini presentations, group discussions and debates were used. On the other hand, individual speaking activities like "Be a celebrity" in which students impersonated one of their favourite celebrities and were asked to give opinions. Questionnaires were given at the end of each week to investigate the students' response towards L2 speaking and the use of group activities in speaking.

\section{Data analysis}

Their participation, behavior and the results from the questionnaire which analyzed their anxiety level facilitated in investigating the attitude of the students towards group activities as a remedy to aid L2 language anxiety in speaking. Both qualitative and quantitative data were analyzed using SPSS and basic data analysis techniques were applied.

\section{Results and Discussion Quantitative data analysis}

The results of the quantitative data were analyzed using percentages of the responses. Initially the background to L2 speaking was investigated by inquiring the usage of English at home, their medium of communication at school, their participation for in-class speaking activities and in-class speaking activities at school (Figure 1).

\section{Figure 1.}

\section{Percentage use of L2 at home}

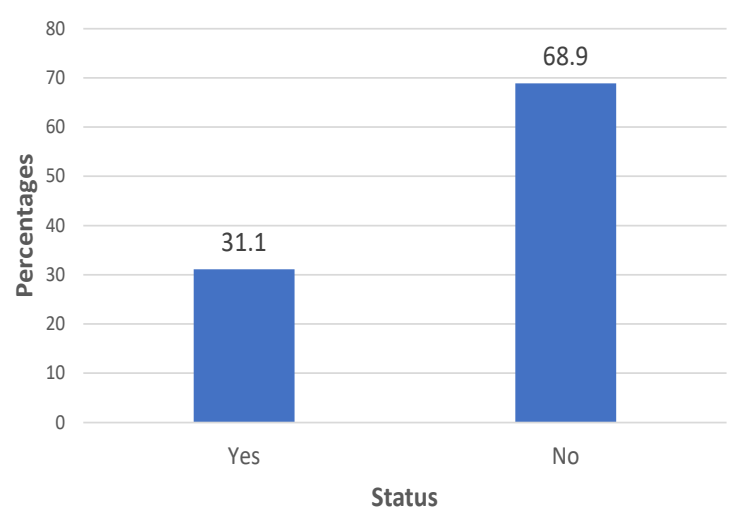

According to Figure 2, it is revealed that 31.1\% students use English at home and $68.9 \%$ do not use L2 at home. This reveals that the sample group does not have a strong background to L2 speaking at home because the majority of them use the vernacular as the method of communication at home.

\section{Figure 2:}

\section{Medium of Communication at school}

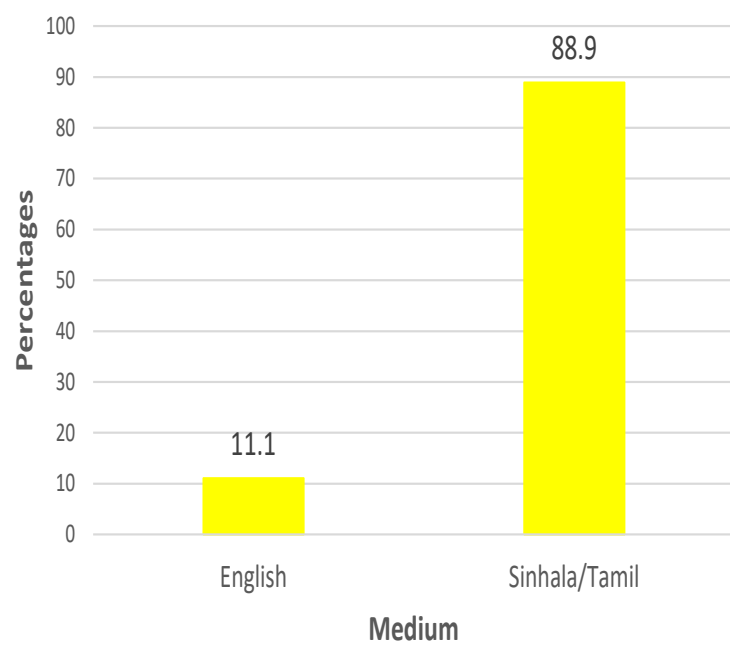

Figure 2 indicates the medium they have used in their secondary education. As can be seen, a very low percentage (11.1\%) has followed their secondary education in English medium. Significantly out of them, $8 \%$ percent stated 
that they have situational anxiety. This highlights that the majority $(88.9 \%)$ does not have a strong background to L2 speaking at school. This argument was further established by their in-class participation for L2 speaking activities at school.

\section{Figure 3.}

In-class participation for speaking activities

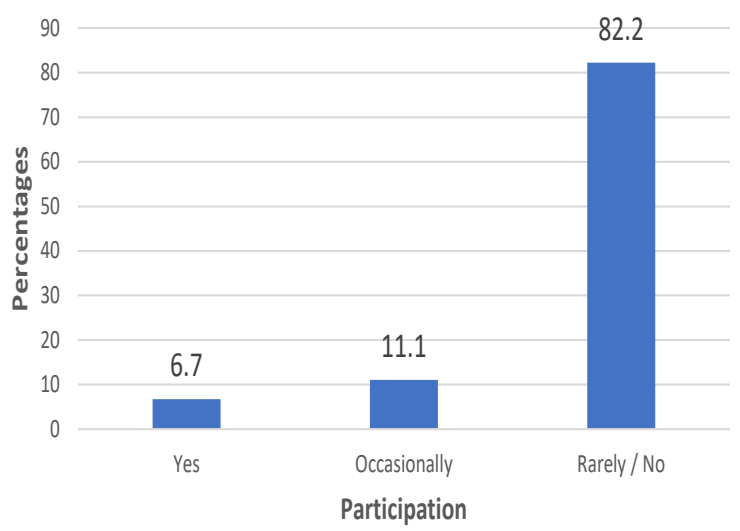

As per Figure 3, participation for L2 speaking is not at a satisfactory level. $82.2 \%$ of the students have said that they have never or very rarely participated in speaking activities. In Sri Lankan education, though English is considered as a main subject, their active participation is very low. This can be identified as one factor which adds to the anxiety levels of the students
Figure 4.

In-class speaking activities

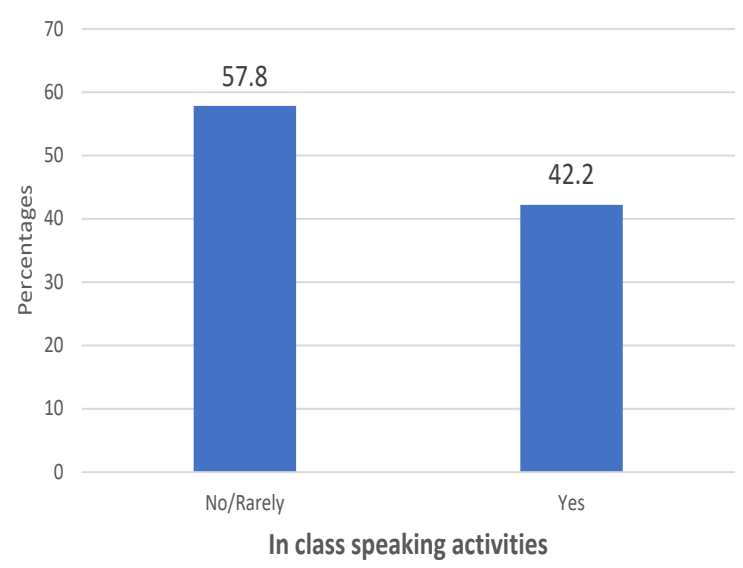

Quantitative data presented in Figure 4 further highlights the lack of exposure students have got to L2 speaking. $57.8 \%$ of them said they hardly had in-class speaking activities at school. This is another important finding because these students have been exposed to English for almost thirteen years as mentioned earlier, and the majority has not done much speaking activities during their secondary education. This can be another reason which adds to the anxiety levels of the students. This argument was further justified by past survey. According to Onwuegbuzie, Bailey and Daley (1991) students who had not followed any foreign language had higher levels of foreign language anxiety than their more languageexperienced friends.

Thus it can be hypothesized that the sample group does not have a strong background to L2 speaking. Past survey (Daubney, 1995) discusses the positive effects of introducing a foreign language to primary school children. Despite having L2 included in their school curriculum, the majority was afraid of L2 speaking. This brings into light the dire need of helping the students. 
Their opinion on the group activities has not changed; they preferred group activities. There was a slight difference in their attitude towards speaking as they said they used L2 for the first time in front of an audience. This highlights the lack of opportunities they have got at school level. As Attanayake (2020) discusses, teaching in South Asian countries are exam -oriented and paper-pencil based. As a result, productive skills are being neglected. So, due to lack of exposure and their attitude, the students have got detached from English speaking and on the other hand it had added to their L2 speaking anxiety levels.

\section{Percentages of attitude towards L2 speaking}

The study continued for three weeks and their attitude towards L2 speaking was monitored. At the end of two weeks, students involved in seven group activities. Some revealed that they spoke in English in front of an audience for the very first time. $7 \%$ of the students stated that speaking is difficult due to linguistic difficulties. At the initial questionnaire $76 \%$ of them said that they did not like individual speaking activities at all. At the end of the second week, they did an individual speaking activity called, "Be a Celebrity" which was a prepared, fun speech. Interestingly 54\% said they liked this activity, but overall, their preference was for group activities because their teammates have helped and motivated them. At the end of this week, a drop in the attendance was observed, noticeably on the day of the mini presentation.
Figure 5.

\section{Attitude towards L2}

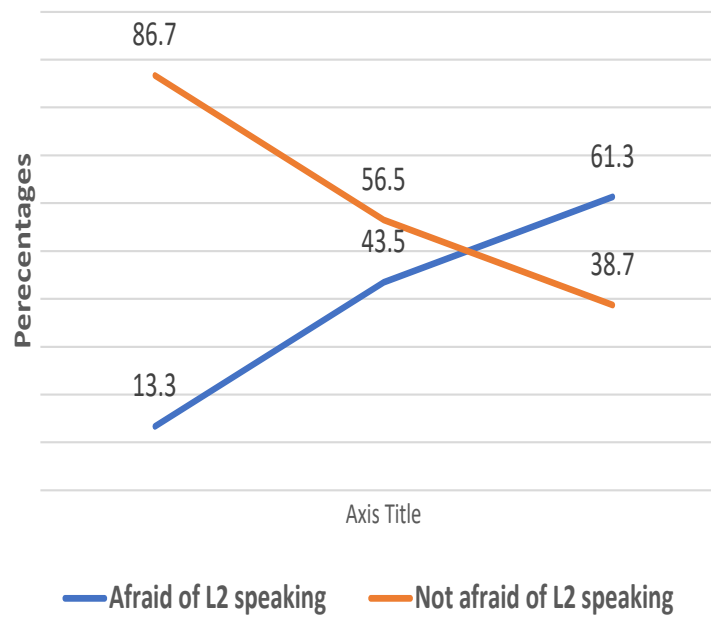

According to Figure 5, during the first week, majority of the students $(86.7 \%)$ has said they are afraid of L2 speaking. At the end of two weeks, $56.5 \%$ of the students said they are afraid of L2, and during the last week it has dropped to $38.7 \%$. In comparison of the two proportions, it was found that percentage of afraid of L2 speaking in week 2 is significantly lower $(p=0.004)$ than that of week 1. Also the proportion of afraid of L2 speaking at week 3 is also significantly lower than that at week 2 at $10 \%$ level. At the beginning, only a minority of the students (13.3\%) has said they are not afraid of L2 speaking. Over the two weeks, the percentage of the students who said they were not afraid of L2 speaking has increased. (61.3\%). When analyzing the above data, a change in their attitude towards L2 Speaking can be noticed. The percentage of students who were afraid of L2 speaking has decreased.

According to the quantitative data, a change can be seen in their attitude towards L2 speaking, but towards the end of three weeks there was a drop in the attendance as illustrated in Figure 5. 
When comparing the proportions displayed in figure 5 , it is evident that the number of students who were afraid of speaking have decreased even though there is a drop in the attendance. As mentioned by the students the group activities in the ESL classroom have helped the students to make an effort to speak as they were supported by everyone.

\section{Analysis of qualitative data}

As discussed in the previous section, there was a change in their attitude towards L2 speaking, but when evaluating their speaking, it was observed that they still had symptoms of speech anxiety. Some common symptoms they had were trembling when speaking, not maintaining eye contact with the audience, stuttering, using filling words, sweating and keeping their hands in the pocket. When observing the discussions within the group, it was noticed that majority switch to L1 when the facilitator is not around. This is an interesting finding where the students choose to switch to L1, irrespective of the constant reminders not to use L1 in the class.

Furthermore, it was observed that fluent speakers took the lead in group discussions, and they were keen on supporting others. Individuals who had linguistic difficulties were assisted by the group members, and they were motivated to speak too.

\section{Conclusions}

The findings of both qualitative and quantitative data proved that using group activitiy as a remedy to reduce anxiety in speaking has a positive impact. The students who have never spoken in front of an audience were given the opportunity to make an effort. When the facilitator was not around, the students used to switch to L1 and thus it is necessary to closely monitor the students to get the full benefit of group activity. Furthermore, there has to be an attitudinal change which should be inculcated from primary and secondary education. If not, the exposure they got for English during their primary and secondary education will not be used well.

As for the findings, the priority given to this productive skill is very low during the secondary education. Majority (57.8\%) has said they had in - class speaking activities very rarely. In fact, speaking has been neglected as this skill is not tested in the exambased curriculum. Though the student had a positive attitude towards group activities, it is necessary to closely monitor the student's activities to get the full benefit of L2 group activities.

It was also revealed that exposure they have got for L2 speaking during their secondary education is very low. It can be suggested that the school curriculum should be designed to give students more opportunities to communicate using L2 starting from primary education irrespective of the medium they study. In fact, speaking skills should be tested during exams and that will create some interest in the students to speak and improve L2.

\section{Acknowledgement}

Firstly, I would like to extend my gratitude to the Management of SLIIT for providing us the opportunity to engage in research work. Secondly, I wish to thank Dean of the Faculty / General Chair, Dr. Malitha Wijesundara and the organizing committee of SICASH 2020 
for creating the platform to groom ourselves as academics. Next, I am extremely grateful to my colleagues of ELTU for their constant motivation and support to complete this research.

\section{References}

Attanayake, A. U. (2000). The Significance of Building Confidence to Speak English as a Teaching Methodology. SLELTEC 2020 Proceedings, British Council and Ministry of Education.

Daubney, M. (2005) Language anxiety: Creative or negative force in the language classroom? $19^{\text {th }}$ Conference of the Association of Portuguese Teachers of English, entitled 'Creativity: A password to successes.

Gardner, R. \& MacIntyre, P. (1993). A student's contributions to secondlanguage learning. Part II: Affective Variables. Language Teaching, 26(1), 1-11. doi:10.1017/S026144480000004.

Horwitz, E.K., Horwitz, M. B., \& Cope, J. A. (1986). Foreign language classroom anxiety. Modern Language Journal, 70(2), 125-132.

Horwitz, E. (2001). Language anxiety and achievement. Annual Review of Applied Linguistics, 21, 112-126. doi:10.1017/S0267190501000071.

McCroskey J.C. and Beatty M.J. (1986) Oral Communication Apprehension. In: Jones W.H., Cheek J.M., Briggs S.R. (eds) Shyness. Emotions, Personality, and Psychotherapy. Springer, Boston, MA.
Neer, M.A. and Kirchner, F.W. (1991) "Classroom Interventions for Reducing Public Speaking Anxiety," Basic Communication Course Annual: Vol. 3 , Article 18.

Onwuegbuzie, A. J., Bailey, P. \& Daley, C. E. (1999). Factors Associated with Foreign Language Anxiety. Applied Psycholinguistics, 20(2), 217-239.

Pribyl, C., Keaten, J. \& Sakamoto, M. (2001). The effectiveness of a skills based program in reducing public speaking anxiety. Japanese Psychological Research.

Saunders, D. \& David, C.(1985):’Playing with a Second Language." Simulation/ Games for Learning 15 166-72.

Shumin, K. (2002) "Factors to Consider: Developing Adult EFL Students' Speaking Abilities," in Methodology in Language Teaching, Cambridge: Cambridge University Press.

Wolpe, J.(1958). Psychotherapy by Reciprocal Inhibition. Palo Alto, CA: Stanford University Press.

Woodrow, L. (2006). Anxiety and Speaking English as a Second Language. RELC Journal.

Young, Dolly, J. (Apr 1, 1992). Language Anxiety from the Foreign Language Specialist's Perspective: Interviews with Krashen, Omaggio Hadley, Terrell, and Rardin, Foreign Language Annals; New York Vol. 25: 157. 